\title{
NUTRITION EDUCATION AND COUNSELING AT HOSPITAL DETERMINES DIETARY ADHERENCE OF DIABETES PATIENTS
}

mulat tirfie bayih ( $\triangle$ mulatbonny@gmail.com )

Bahir Dar University

\section{Sebsbie Tadesse}

University of Gondar

Haile Woldie

University of Gondar

Teshager Woldegiorgis Abate

Bahir Dar University

Minyichil Birhanu Belete

Bahir Dar University

Research article

Keywords: Nutrition education , Diabetes, Diet, Ethiopia

Posted Date: July 15th, 2019

DOI: https://doi.org/10.21203/rs.2.11382/v1

License: (c) (1) This work is licensed under a Creative Commons Attribution 4.0 International License.

Read Full License 


\section{Abstract}

ABSTRACT Background: Adherence to healthy meal plan can delay and prevent complications from diabetes. However, feeding habits of the patients is not well known in many developing countries including Ethiopia. Objective: The purpose of this study was to assess the dietary adherence and associated factors among diabetes patient at Felege Hiwot Referral Hospital, Bahirdar City Northwest Ethiopia. Methods: Institution-based cross-sectional study was conducted among systematically selected 385 diabetes patients from March to April, 2017 at Felege-Hiwot Referral hospital, Bahir Dar Northwest Ethiopia. Quantitative data were collected by using a pre-tested and structured questionnaire. To supplement their experiences, views and perception, participants were selected purposely for in-depth interviews. Logistic regression was used to identify associations between dependent and explanatory variables. Statically significant was considered at $\mathrm{p}$ value $<0.05$ with $95 \% \mathrm{Cl}$. The qualitative data were analyzed in content line by line with quantitative findings. Results: The overall proportion of poor dietary adherence among diabetes patients was $46.8 \%$ (95\% Cl: 41.1- 52.0). Living in rural (AOR=3. $75 ; 95 \% \mathrm{Cl}$ : 2.12-6.63), duration of diabetes less than 5 years (AOR=2. 81; 95\% Cl: 1.22-6.50), didn't get nutrition education (AOR=5. 88; 95\% Cl: 3.30-10.48), poor social support (AOR=3. 84; 95\% Cl: 1.74-8.46) and didn't make choices on food when they ate out ( $A O R=3.49 ; 95 \% \mathrm{Cl}$ : 2.09-5.81) were significantly associated with poor dietary practice. Conclusion: Considerable numbers of diabetes patients in this study were nonadhered to the recommended diet and to improve their dietary practice; attention should be given to nutrition education. Keywords: Nutrition education , Diabetes, Diet, Ethiopia.

\section{Background}

Diabetes is a chronic condition that occurs when the body cannot produce enough insulin or cannot use insulin, and presented with raised levels of glucose in the blood. Over time, high levels of glucose in the blood cause damage to many tissues in the body, leading to the development of disabling and lifethreatening health complications such as coronary artery and peripheral vascular disease $(1,2)$.

Today, diabetes is the most common non-communicable diseases globally (3). It is the fourth or fifth leading cause of death in most high-income and epidemic in many low- and middle-income countries (1). Complications from diabetes are resulting in increasing disability, reduced life expectancy and enormous health costs for virtually every society $(1,2)$. DM is the most challenging health problems in the 21 st century and also in each year, 3.2 million people around the world die from complications associated with it $(2,4)$.

According to World Health Organization report in 2016, the number of people with diabetes has risen from 108 million in 1980 to 422 million in 2014 and also the global prevalence of diabetes among adults over 18 years of age has risen from $4.7 \%$ in 1980 to $8.5 \%$ in 2014 (3). According to 2015 African international diabetes federation report more than 14 million people in the Africa have diabetes and this figure will be more than double by 2040. In Ethiopia, there were over 1.33 million cases of diabetes in $2015(5,6)$. 
Ongoing patient self-management, education and support are critical to preventing acute complications and reducing the risk of long-term complications (7). Therefore, a healthy meal plan and being active can keep blood glucose level, blood pressure, and cholesterol in target ranges (8). In different scholars found that most DM patients follow a food plan (9). However, in another study reported that a diabetes patient poorly adhered to dietary advice (10). In Africa different studies revealed that good adherence of dietary practice of diabetes patients. Such as in Botswana 63\%; and in south Nigeria 76\%; in Egypt $66.0 \%$ of Diabetes patients were adhered to dietary practice (11-15). The prevalence of dietary adherence among diabetes patient in Ethiopia was ranged from $51 \%-55 \%$ (16).

Different studies showed that dietary practices in diabetes patient was most strongly associated with difference variables such as nutrition education (17); higher education level, having strong family support, (18); female gender, increasing age, joint or extended family members, (10); lower personal income, occupation (19); lack of information on healthy diet, eating out and financial constraints, lack of knowledge about the diseases and inadequate and inaccurate dietary advises $(12,20)$; not getting nutrition education in hospitals, despondency, facing difficulty to choose foods, non- availability of fruits and vegetables, thinking about the high cost of foods (16).

Therefore, the aim of this study was assessing the dietary adherence and associated factors among diabetes patients.

\section{Methods}

\section{Study design, settings and participants}

Institution-based cross-sectional study was conducted from March to April, 2017 at Felege- Hiwot Referral Hospital which is found in Bahir Dar city administration, Northwest Ethiopia. Bahir Dar is a capital city of Amhara region and located $565 \mathrm{kms}$ from Addis Ababa, the capital city of the country. Felege Hiwot referral hospital is the public hospital in the city. According to six month performance report of the hospital, it serves the population in the region and those from Beneshangul Gumuez population as a referral center. It provides promotion, preventive, curative and rehabilitative services to them. In outpatient chronic follow up department approximately 220 adult diabetes mellitus patients are seen weekly(21).

All diabetes patients aged greater than or equal to 18 years old and who visited the outpatient chronic follow up department for one and above year were participating in the study. On the other hand, those who were critically ill and unable to participate in the interview were excluded.

\section{Sample size determination and Sampling procedure}

The required sample size of the study was determined using a single population proportion formula. The prevalence of poor dietary practice among diabetic patients $(P)$ was taken as $51.4 \%[16]$ and with the assumptions of: a $95 \%$ of confidence level and $5 \%$ margin of error. Based on this assumption and adding $10 \%$ non-response rate the required sample size was 404 . 
Systematic random sampling technique was employed to recruit a total of 404 study subjects which is based on the number of diabetes mellitus outpatients who had an appointment during data collection period in the hospital (referring from registration book). These patients were divided for representative sample size and the individual approached through calculating sampling interval $(K=N / n)$; Where $N$ is the total number of diabetic patient who had appointment during data collection period (880) and $n$ is the calculated final sample size (404).

Finally, the determined samples for each date was achieved through exit interview every 2 ndinterval within four weeks of working days. The starting point was selected randomly by lottery method to take as a starting patient for the interview.

Based on the decision to collect data over the course of one month, the patient coming to the clinic for a follow-up service was interviewed until the total sample size reached and one study subject was recruited only once.

For in-depth interview, purposive sampling was employed to select few participants among all diabetes patients who were on treatment follow-up at the Felege Hiwot Referral Hospital. Because of the experience of living with DM was considered very fundamental for effective deliberation on dietary practice experience, only patients who had DM at least five years and age greater than 18 years of both male and female diabetes patients were recruited to participate in the study. We tried to include patients believed to be interactive, open minded and those who were willing to participate in the study until information saturation.

\section{Data collection procedures and quality control}

Data were collected by interviewing eligible participants using a pretested and structured questionnaire. Patients were given an orientation on the protocol and specific details concerning participation in the study. Data were collected by using a pretested structured questionnaire developed by reviewing different related articles that assessed diabetes risk factors, demographic characteristics, wealth status, duration of diabetes, behavioral and social factors $(10,12,16,18-20,22-30)$. Measurements of wealth index were developed from 2011 Ethiopian demographic and health survey (30).

Dietary adherence of DM patients was assessed by using questionnaires developed by Amelmal Worku's modified form of the eight-item Morisky medication adherence scale (MMAS-8) $(16,18,31,32)$. It had 11 components and was computed by taking the mean value to classify the respondents follow good and poor dietary adherence. Accordingly, respondents were allowed to choose correct answers by indicating whether a given statement is Yes or No. Finally, the dietary practice of respondents was scored and computed for dietary practice variables.

Social support was measured using the Oslo-3 Social Support Scale (OSS-3) with three questions. The response categories were assessed independently for each of the three questions, and a sum score was 
created by summarizing the raw scores. The sum score scale ranging from $3-14$, which was then operationalized into "poor support" 3-8, "moderate support" 9-11and "good support"12-14[37].

In case of qualitative data, an interview-guide questions were prepared in Amharic (local language of respondents) to elicit information from participants about their experiences, views that influenced their dietary practice. Participants were asked a series of open-ended questions that reviewed all topics systematically and encouraged participants to share their perspectives. The participants who were willing to interview were appointed for an interview at a venue of their choice. The interview was conducted face to face by the principal investigator. Audio recorder and transcribed verbatim were applied during the interview. The interviewer was probed participants to obtain additional information on interesting topics that emerged and to clarify ambiguous comments.

To ensure quality of data, pre-test was conducted using $5 \%$ of the sample on diabetes patient who were not included in the main study area before two weeks to assess instrument simplicity, flow and consistency. Amendments were made accordingly after the pre-test. Data were collected by four trained, diploma nurses and two supervisors (BSc nurse). Additionally, the completeness of the questionnaire was checked by supervisors and principal investigators every day and incomplete questionnaire was discarded. For qualitative data quality was maintained by daily data transcription. That means documenting the data both in written form and in audio recording and translates the concepts directly in word to word.

\section{Data analysis}

The collected quantitative data were coded and entered into the computer using Epi data version 3.1. Then it was exported into the windows of Statistical Package for Social Science (SPSS) version 20 for data analysis. Household wealth index was determined from asset data using principal component analysis (PCA). First, variables were coded between 0 and 1, and then the variables entered and analyzed using PCA and those variables which have commonality values greater than 0.5 were used to produce factor scores. Next, the produced factor scores were computed to produce a common factor score. Finally, the common factor score was categorized into three categories (tertile) as (poor, middle and rich). The frequencies, percentage, mean and standard deviation were described using tables and graphs. Logistic regression was applied to assess the association between dependent and explanatory variables. Both Bivariate and multivariable analysis were applied to determine factors affecting dietary practice. Those independent variables at $\mathrm{P}$-Value of 0.2 in the bivariate analysis were fitted to the multivariable analysis. The degree of association was interpreted by using adjusted odd ratios with $95 \%$ confidence intervals and P-value less than 0.05 was considered statistically significant.

In qualitative data analysis, the investigator was transcribed the audio-records on the same day as the completion of the interviews enabling him to capture observations of the non-verbal points by linking the audio-recorded interviews, field notes, and the researcher's memory of the event. Data gathered from the transcription of the interviews was organized by individual questions with the corresponding verbatim answers from the participants. The instigator was passed the following steps for analysis. 1)each 
recorded interview was downloaded into the researcher's laptop; 2) recorded interviews were downloaded to discuss creating a backup copy, 3) a verbatim translation of the transcripts from Amharic into English was done by the researcher. The translation was checked by listening to the recorded interviews again whilst reading the computer files, 4) after completing the transcriptions, computer folders, download disks, and transcribe, and translate notes were labeled using identification number, date and place of the interview to make the connection back at any time when the researcher was in need, and to ensure confidentiality. The responses were coded line by line to find commonly used words or descriptions of experiences, which was labeled to characterize the answers and provide illustrative quotations reflecting these descriptions.

\section{Results}

\section{Socio-demographic characteristics of respondents}

A total of 385 diabetes patients who had treatment follow - up were included in the data analysis with a response rate of $95.3 \%$, out of this $74.5 \%$ had type 2 and $56.4 \%$ were males. The mean ( $\pm S D$ ) age was $42.5( \pm 15.13)$. More than half of the participants, $62.6 \%$ were married. $29.1 \%$ were unable to read and write. (Table1)

Table 1: Socio-demographic characteristics of diabetes patient who were on treatment follow-up at Feleghiwot referral hospital, Bahirdar city, Northwest Ethiopia 2017(N=385).

\section{Magnitudes of dietary practices towards DM}

The overall proportion of poor dietary adherence among diabetes patients who was on treatment follow up at Felege-hiwot referral hospital was $46.8 \%$ [95\% Cl: $(41.1,52.0)]$. The proportion of poor dietary adherence among type $2 \mathrm{DM}$ and type $1 \mathrm{DM}$ was almost similar (46.7\%) and (46.9) respectively. Dietary adherence was becoming desirable with increase duration of diabetes. Such as, less than 5 years of duration (52.6\%), 5-10 years of duration (48.7\%) and above 10 years of duration (22.0\%) had poor dietary practices respectively. The proportions of poor dietary practice, slightly higher in female (49.4\%) than male (44.7\%); and decrease with current age category (15-30, 31-60 and $>60$ ) were $54.6 \%, 45.7 \%, 33.3 \%$ respectively. Of the total diabetes patients, $50.6 \%$ missed to include fruits to their meal plan (Table2).

This is supplemented by qualitative findings.

Comply dietary plan with everyday life: three out of five respondents said that it was easy to comply their meal plan with their everyday life. They were included all necessary meals like more vegetables and fruit, lentil and Shiro to their daily meal plan.

A 35 years old female respondent replied "For me it easy to follow my meal plan because they told me easy and accessible foods, but it was difficult if you told to eat more meat, egg, milk and chicken wot 
which are more expensive. Now I told to eat lentil, Shiro, cabbage, spinach, banana and orange which are easily available". By Show smile face.

The rest two said it was difficult to include all the food to their meal plan, but they ate what is available in their house that their economy allowed.

An 18 years old male diabetes patient said "I ate fruit once a week and this even so if I have money to buy otherwise, I ate only Shiro with injera and even I miss my breakfast". By shaking his hand and nodding his head.

Table 2: Magnitude of dietary practice of diabetes patients who were on treatment follow-up at Felegehiwot referral hospital, Bahirdar city, Northwest Ethiopia, 2017 ( $n=385)$.

\section{Psychosocial, health and information factors of dietary practice in diabetes patients}

Of the 385 diabetes participants, $79.5 \%$ had no chronic diseases other than DM that affect their dietary practices; $70.1 \%$ had got nutrition education, $32.7 \%$ got printed nutritional education materials; $56.1 \%$ had poor social support and $50.9 \%$ did not done regular physical exercises, $94 \%$ had not used substance, $81.8 \%$ did not check their fast blood sugar regularly and $55.3 \%$ make a good choice when eat themselves out (table 3 , fig1).

Qualitative findings support this.

Allowed food:- Only two respondents said all food is allowed but, not excess in amount; less frequently and quantity allowed food or sugar, wheat bread, fats, etc. Whereas more frequently and quantity allowed foods are vegetables (cabbage) and fruit (mango).

A 77 years old man said that "I got printed material which is important to me and for all diabetes patients. It contains food list like usual consumed food, less likely consumed food and totally restricted food".

Restricted food: three respondents replied lists of restricted food like wheat bread, sugar, potato and alcohol, but barley bread most recommended food to consume secondary to vegetables and fruit.

"Sugar and alcohol is totally restricted especially sugar". "If you eat potato your blood sugar is increased so it is restricted to consumed"

Table 3: psychosocial, health and information related characteristics of diabetes patients who were on treatment follow-up at Felege hiwot referral hospital, Bahirdar city Northwest, Ethiopia 2017(n=385).

\section{Factors associated with dietary practices}

The overall proportion of poor dietary adherence among DM was $46.8 \%$ (95\% Cl: 41.1- 52.0). Poor dietary practice was statistically significant with residency, duration of DM, nutritional education, making food choices when eat out and social support. Living in rural 3.75 times more likely poor dietary practices than living in urban (AOR=3.75; 95\% Cl: 2.12-6.63). Diabetes patients who had less than 5 years duration of 
diabetes were 2.81 times more likely to have poor dietary practice than who had more than 10 years duration ( $A O R=2.81 ; 95 \% \mathrm{Cl}: 1.22-6.50$ ), those who had 5-10 years duration of diabetes were 2.79 times more likely to have poor dietary practice than who had more than 10 years (AOR=2. 79; $95 \% \mathrm{Cl}$ : 1.15 6.73). Those who had not got nutrition education were 5.88 times more likely had poor dietary practice than those who had got nutritional education (AOR=5. 88; 95\% Cl: 3.30-10.48).

Qualitative findings support this:

A 48 years old female respondent said "At the hospital, I didn't get information what to eat, they simply told me your diabetes was in good conditions and don't take sweet things if you take it your blood glucose will raise."

Ate out of their home without making choice of food was 3.49 times more likely had poor dietary practice than those who had made choices (AOR=3. 49; 95\% Cl: 2.09-5.81). This again supplemented by qualitative findings.

Eat out: All respondents were saying that it was difficult to get their meal plan when they ate out like a restaurant and ceremony they ate what was prepared there. $A 35$ years old female respondent said that "when I called away to the festive meal I couldn't follow my meal plan because they pushed me to drink and eat their festive meal e.g. when they make chicken with they add more butter to make it sweet and push me to eat and even said to me there is no sugar in this alcohol than I eat and drink it by bashfulness" by nodding her head.

Place and Nature of work: the data got from interview showed that the work place and the nature of work make challenge to them to follow their meal plan with related to their health condition.

A 70 years old male said that " for me no problem because I am pensioner and I always be in my house but it is difficult for those who are daily laborer and field workers they always eat out because of their work nature".

Another 25 years old female lady said that "Hum, I ate what is available at the restaurant because am hungry and no chance to choice, even in my workplace ether is no better restaurant."

Being poor social support 3.84 times had more likely poor dietary practice than those who had strong social support (AOR=3. 84; 95\% Cl: 1.74-8.46) (Table 4).

Table 4: Bivariate and multivariable analysis of factors associated with dietary practice of diabetes patients who are on treatment follow up at Felege- hiwot referral hospital, Bahirdar city, Northwest Ethiopia 2017.

\section{Discussions}


In Ethiopia, especially in the study area, there was limited information about the dietary practices of patients with diabetes mellitus. Thus, our study has tried to assess the dietary adherence and associated factors among diabetes patients who were on treatment follow up at Felege hiwot referral hospital outpatient department. In this study, the overall proportion of poor dietary practice was $46.8 \%(95 \% \mathrm{Cl}$ : 41.8-51.9); this was in line with similar studies conducted in Addis Ababa, Saudi Arabia, India and RiyadhSaudi Arabia $(16,26,33-34)$. But it was different from a study conducted in Egypt, Acca-Ghana and Botswana $(12,15,33)$. This difference might be due to social, economic and culture characteristic difference, patients' understanding and perceptions of the role of diet and the clinic set up with the availability of nutritionist. In this study nutrition education given at the hospital had strongly associated with the dietary practice which was agreement with a study conducted in Addis Ababa, China, India, Botswana and South Africa (16). This is the fact that if diabetes patients didn't get information on what to eat, the importance of nutrition in the management of their diabetes and variety of food that they consumed they wouldn't follow their meal guideline.

Not making food choice when they eat out was the other factor for poor dietary practice which was in line with studies conducted in Botswana and Addis Ababa $(12,16)$. This is the fact that diabetes patients don't get their recommended diet when they ate out of their home like restaurant and social gatherings, and the homes of extended families and friends.

In our study, social support was strongly associated with the dietary practice of diabetes patients, which was in line with other studies, like in Niger and Bahrain $(18,34)$. This due to the fact that when they couldn't get help from social including their family they may feel despondent, then they might be missing their dietary meal plan, including taking the excess sweetness and alcohol. When people living with diabetes and didn't have support from their close social networks, they might be feeling stressed to the life, often generating feelings of isolation, frustration, anger and guilt that might not be care their diet. In our study, duration of diabetes was the other factor for poor dietary practice which was early diagnosed diabetes patients were more likely to have poor dietary practice. This was in line with the study conducted in northwest Iran (35). This is the fact that when the diabetes patients' contacts of their health caregiver for the first time everything told to them might be new and their knowledge was not that much better. But when the time of follow up increased they become familiar to the services and rich in information even ask the caregiver what make themselves challenge on their dietary practice and then have a good meal plan ahead.

However, handful of earlier published articles reported residency was not significantly associated with dietary practice of $D M$, but in our study it was significantly associated $[16,18,24]$. This might be possibly those who were living in the rural might not get information by other means other than orally told because in real situation, especially in this study set up they were illiterate and could not read what was given them by printed materials. Also, those who lived in the rural had a minimal perception about their health and diet because they were engaged with field work. In fact, they produce different fruit and vegetables, but they used them as sources of money rather consumption and brought to the market and sold to those who lived in urban peoples. 


\section{LIMITATIONS OF STUDY}

Limitations were social desirability bias and discuss some of the findings and because the study-design was cross-sectional method, the direction of causal relationships between variables can't always be determined.

\section{CONCLUSIONS}

Our study revealed that a significant number of DM patients had poor dietary practice. Since nutrition education, duration of DM, social support, making choices when eat out the home and residence were factors associated with poor dietary practice. These finding suggest the needs to work on integrated intervention on nutrition education, social bond and meal plan when eat at home.

\section{RECOMMENDATIONS}

We recommend the inclusion of brief intervention strategy for nutritional education and to have nutrition counseling unit in diabetes care at the hospitals. As we know brief interventions to routine nutrition education program for all patients at the outpatient department level has the potential to improve dietary practice in DM patient that minimized long and short term complication and also increase quality of life. We also recommend further population based research to explore specific factors such as the association found in this study that indicated that residence was associated with high level of poor dietary practice. Where possible, conduct a research by using the longitudinal model and estimation of portion size of their diet and repeated 24 hour recall.

\section{List Of Abbreviations}

ADA, American Diabetes Association; AOR, Adjusted Odds Ratio; Cl, Confidence Interval; COR, Crude Odds Ratio; DM, Diabetes Mellitus; EDA, Ethiopian Diabetes Association; EDHS, Ethiopian Demographic and Health Survey; FBG, Fasting Blood Glucose; IDF, International Diabetes Federation; MNT, Medical Nutrition Therapy; NCD, Non Communicable Disease; NNP, National Nutrition Program; PCA , Principal Component Analysis; SADA, South African Diabetes Association; SPSS, Statistical Package for Social Sciences; and WHO, World Health Organization

\section{Declarations}

\section{Ethical approval and consent to participants}

Ethical clearance was obtained from the University of Gondar institute of public health review board committee. Permission and supportive letter were obtained from respective hospital chief executive officer before data collection. Participation was voluntary and information also were collected anonymously after obtaining written informed consent from each respondent by assuring confidentiality throughout the data collection period and audio recording. 
Not applicable

Availability of data and material

The dataset used and /or analyzed this study are available from the correspondent author on reasonable request.

Competing interests

We conclude that there is no competing of interest.

Funding

Not applicable

Acknowledgments

We would like to offer our in-depth gratitude to the data collectors, participants and hospital workers, especially who works in the diabetes follow up outpatient departments for their support to us.

\section{References}

1. IDF. International Diabetes Federation ,Diabetes Atlas Seventh Edition. 2015.

2. Richard Sicree JS, Paul Zimmet Baker IDI Heart and Diabetes Institute The Global Burden ,Diabetes and Impaired Glucose Tolerance IDF Diabetes Atlas fourth edition

3. World Health Organization Global report on diabetes, Geneva. 2016.

4. The IDF consensus worldwide defnition of the metabolic syndrome. 2006.

5. Africa IDF. Diabetes Prevalence Report. 2015.

6. association ed. EThiopian diabetes association diabetes prevalence report 2015. 2015.

7. American Diabetes Association Nutrition Recommendations and Interventions for Diabetes. DIABETES CARE. 2008; 31.

8. American Diabetes Association. Standards of Medical Care in Diabetesd. The journal of clinical and applied research and education; WWW. Diabetesorg/diabetescare 2016;39

9. do Nascimento dO, Valzimeire Neto, Abelardo, de Souza, Ana, Façanha, Thaís, Montenegro, Renan, Guedes, Maria. Demographics factors and food consumption of diabetes patients type 1 in outpatient care of a Federal University Hospital. Diabetology \& Metabolic Syndrome. 2015;7:238. 
10. Janaki Parajuli1* FS, Narbada Thapa3,4 and Liaquat Ali4. Factors associated with nonadherence to diet and physical activity among nepalese type 2 diabetes patients; a cross sectional study. BMC Research Notes http://wwwbiomedcentralcom/1756-0500/7/758. 2014;7.

11. A R Isara LO, and D O Olaoye,. Non-medical management practices for type 2 diabetes in a teaching hospital in southern Nigeria. African Journal of Diabetes Medicine. November 2014;22

12. Ogunbanjo2 ABGLHMNHMIGGA. Non-adherence to diet and exercise recommendations amongst patients with type 2 diabetes mellitus attending Extension II Clinic in Botswana. http://wwwphcfmorg phcfm. 13 may 2013;5(1.457).

13. T. Ralineba1 MLNaNHS. Knowledge and Practices Associated with Diabetes among Patients with Chronic Diabetes Mellitus in Rural Areas of Vhembe District, Limpopo Province, South Africa. Kamla-Raj J Hum Ecol,. 2015 51:193-201

14. El-Abbassy A. Non-Adherence to lifestyle Modification Recommendations of Diet \& Exercise amongst Diabetes Patients. IOSR Journal of Nursing and Health Science (IOSR-JNHS) (Jul - Aug. 2015);4(4).

15. Christina A. Nti DAaCO-O. Relationship between dietary practices, physical activity and body mass indices of type 2 diabetes attending a clinic in Accra, Ghana. Journal of Public Health and Epidemiology. April 20168 (2141-2316): 60-6.

16. Worku A SM, Molla M. Dietary practice and associated factors among type 2 diabetes patients: a cross sectional hospital based study, Addis Ababa, Ethiopia. Springerplus. 2015;4:15.

17. Huan Wang ZS, Yanhui Ba, Lin Zhu and Ying Wen. Nutritional and eating education improves knowledge and practice of patients with type 2 diabetes concerning dietary intake and blood glucose control in an outlying city of China, 2013

18. Najla Shamsi MD1 ZSM, Zahra AlNahash MD1,Shawq AlMuhanadi MD1 Faisal Alnasir MICGP, FRCGP, FFPH, PhD2,. Factors Influencing Dietary Practice Among Type 2 Diabetes Patients in Bahrain, . Bahrain Medical Bulletin. September 2013;35.

19. Kee Fong Tiew1 YMC, 2, Munn Sann Lye3, Seng Cheong Loke2,4. Factors Associated with Dietary Diversity Score among Individuals with Type 2 Diabetes Mellitus. J HEALTH POPUL NUTR 2014;32 (16060997| \$ 5.00+0.20):665-76.

20. Nthangeni G, Steyn, N. P., Alberts, M. ,Steyn, K., Levitt, N. S. , Laubscher, R., Bourne, L., Dick, J., Temple N. Dietary intake and barriers to dietary compliance in black type 2 diabetes patients attending primary health-care services. Public Health Nutr. 2002;5(2):329-38.

21. Felege-Hiwot Refferal Hospital Six Month Report. 2017. 
22. Al-Kaabi JA-M, F. Saadi, H. Afandi, B. Parkar, H. Nagelkerke, N. Assessment of dietary practice among diabetes patients in the United arab emirates. Rev Diabet Stud. 2008;5(2):110-5.

23. Badreldin A. Mohamed 1 AMA, Abdalla A. Saeed 2 and Ibrahim A. Bani 3. Dietary practices among patients with type 2 diabetes in Riyadh, Saudi Arabia. Journal: Food, Agriculture and Environment (JFAE) Online ISSN: 1459-0263 Publisher: WFLWFL Publisher science and Technology. 2013;11( I 2).

24. Birhanu3 EHWHMTBZ. Self-care practice and glycaemic control amongst adults with diabetes at the Jimma University Specialized Hospital in south-west Ethiopia: A cross-sectional study. Afr J Prm Health Care Fam Med. may 2012;4(i1.311).

25. Junyi Jiang HQ, Genming Zhao, Yi Zhou, Zhijie Zhang, Hong Zhang, Qingwu Jiang, Qiao Sun, Hongyan Wu, Liming Yang, Xiaonan Ruan, Wang-Hong Xu. Dietary Fiber Intake Is Associated with HbA1c Level among Prevalent Patients with Type 2 Diabetes in Pudong New Area of Shanghai, China. PLOS ONE I wwwplosoneorg October 16, 2012; 7 (46552).

26. Martil Chacko1 KBRS, 2Professor,. Dietary Practices among Type 2 Diabetes Patients - A CrossSectional Study from a Major City in India. International Journal of Health Sciences and Research wwwijhsrorg 24/03/2016(2249-9571).

27. Nthangeni GS, N. P. Alberts, M. Steyn, K. Levitt, N. S. Laubscher, R. Bourne, L. Dick, J. Temple, N. Dietary intake and barriers to dietary compliance in black type 2 diabetes patients attending primary health-care services. Public health nutrition. 2002;5(2):329-38.

28. Ozcariz SGBC, O. Cembranel, F. Peres, M. A. Gonzalez-Chica, D. A. Dietary practices among individuals with diabetes and hypertension are similar to those of healthy people: a population-based study. BMC Public Health. 2015;15:479.

29. Dalgard OS DC, Lehtinen V, Vazquez-Barquero JL, Casey P, Wilkinson, G ea. Negative life events, social support and gender difference in depression: A multinational community survey with data from the ODIN study. Soc Psychiatry Psychiatr Epidemiol 2006; 41:444-51.

30. ETHIOPIAN DEMOGRAPHIC AND HEALTH SURVEY 2011.

31. South africa diabetes association, general dietary advise guide line 2011.

32. Morisky DE, MR D. Improving the measurement of self-reported medication nonadherence. J Clin Epidemiology 2011;64:255-7.

33. M. E, Mahfouz, Awadalla HI. Compliance to diabetes self-management in rural El-Minla, Egypt. Cent Eur J Public Health. 2011;19 (1):35-41.

34. Okolie Uchenna, Ehiemere ljeoma, Ezenduka Pauline a, Sylvester O. Contributory Factors to Diabetes Dietary Regimen Non Adherence in Adults with Diabetes. International Journal of Social, Behavioral, 
Educational, Economic, Business and Industrial Engineering 2010

35. Zahra Yekta (MD)a* RPMa, Mohammad Reza Aghassi (MD)a, Nastaran Ashragh (MD)b, Leila Ravanyar (MSc)a, Mohammad Yossef Rahim Pour (MSc)a. Assessment of Self-Care Practice and Its Associated Factors among Diabetes Patients in Urban Area of Urmia, Northwest of Iran. Journal of Research in Health Sciences. 2011;11(1).

Figure:1

Psychosocial factors of dietary adherence among diabetes patients who were on treatment follow-up at Felege-hiwot referral hospital, Bahirdar city, Northwest Ethiopia 2017.

\section{Tables}

TABLE 1: SOCIO-DEMOGRAPHIC CHARACTERISTICS OF DIABETES PATIENT WHO WERE ON TREATMENT FOLLOW-UP AT FELEG- HIWOT REFERRAL HOSPITAL, BAHIRDAR CITY, NORTHWEST ETHIOPIA 2017(N=385). 


\begin{tabular}{llc}
\hline Variables & Frequency & Percentage \\
\hline Sex & 168 & \\
Female & 217 & 43.6 \\
Male & 108 & 56.4 \\
Age in year & 232 & 28.1 \\
15-30 & 45 & 60.3 \\
30-60 & & 11.7 \\
Above 60 & 102 & \\
Marital status & 241 & 26.5 \\
Single & 26 & 62.6 \\
Married & 16 & 6.8 \\
Divorced & & 4.2 \\
Widowed & 112 & \\
Educational status & 73 & 29.1 \\
Unable to read and write & 69 & 19.0 \\
Able to read and write & 50 & 17.9 \\
Grade 1-8 & 81 & 13.0 \\
Grade 9-12 & & 21.0 \\
Diploma and above & 128 & 33.2 \\
Wealth status & 136 & 35.3 \\
Poor & 121 & 31.4 \\
Middle & & \\
Rich & 81 & 21.0 \\
Occupational status & 136 & 35.3 \\
Farmer & 50 & 13.0 \\
Civil servants & 65 & 16.9 \\
Merchant & 53 & 13.8 \\
Housewife & & \\
Daily laborer & & \\
\hline
\end{tabular}

Table 2: Magnitude of dietary practice of diabetes patients who were on treatment followup at Felege-hiwot referral hospital, Bahirdar city, Northwest Ethiopia, 2017 ( $n=385)$. 


\begin{tabular}{|c|c|c|}
\hline Variable & Frequency & Percent \\
\hline \multicolumn{3}{|c|}{ Do you forget to plan the meals you eat ahead? } \\
\hline Yes & 148 & 38.4 \\
\hline No & 237 & 61.6 \\
\hline \multicolumn{3}{|c|}{ Did you miss your dietary plan yesterday? } \\
\hline Yes & 186 & 48.3 \\
\hline No & 199 & 51.7 \\
\hline \multicolumn{3}{|c|}{$\begin{array}{l}\text { Over the past two weeks, were there any days when you did not take your dietary } \\
\text { plan properly? }\end{array}$} \\
\hline Yes & 161 & 41.8 \\
\hline No & 224 & 58.2 \\
\hline \multicolumn{3}{|c|}{ Do you sometimes forget to comply your dietary plan with everyday life? } \\
\hline Yes & 153 & 39.7 \\
\hline No & 232 & 60.3 \\
\hline \multicolumn{3}{|c|}{$\begin{array}{l}\text { When you feel like your DM is under control, do you sometimes stop taking your } \\
\text { dietary plan? }\end{array}$} \\
\hline Yes & 111 & 28.8 \\
\hline No & 274 & 71.2 \\
\hline \multicolumn{3}{|c|}{ Do you ever feel hassled about sticking to your dietary plan? } \\
\hline Yes & 231 & 60.0 \\
\hline No & 154 & 40.0 \\
\hline \multicolumn{3}{|c|}{ Did you have Feelings of dietary deprivation? } \\
\hline Yes & 308 & 80.0 \\
\hline No & 77 & 20.0 \\
\hline \multicolumn{3}{|c|}{ Are you rigid, instead of flexible eating to control your DM? } \\
\hline Yes & 199 & 51.7 \\
\hline No & 186 & 48.3 \\
\hline \multicolumn{3}{|c|}{ Do you miss to include fruits in your food daily? } \\
\hline Yes & 195 & 50.6 \\
\hline No & 190 & 49.4 \\
\hline \multicolumn{3}{|c|}{ Do you miss to include vegetables in your food daily? } \\
\hline Yes & 169 & 43.9 \\
\hline No & 216 & 56.1 \\
\hline \multicolumn{3}{|c|}{ Do you forget to cut down butter and fat intake in your food? } \\
\hline Yes & 152 & 39.5 \\
\hline No & 233 & 60.5 \\
\hline
\end{tabular}

Table 3: psychosocial, health and information related characteristics of diabetes patients who were on treatment follow-up at Felege hiwot referral hospital, Bahirdar city Northwest, Ethiopia 2017(n=385). 


\begin{tabular}{|c|c|c|}
\hline Variables & Frequency & Percent \\
\hline \multicolumn{3}{|l|}{ Duration of DM } \\
\hline$<5$ & 209 & 54.3 \\
\hline $5-10$ & 117 & 30.4 \\
\hline$>10$ & 59 & 15.3 \\
\hline \multicolumn{3}{|l|}{ Chronic diseases other than DM } \\
\hline Yes & 79 & 20.5 \\
\hline No & 306 & 79.5 \\
\hline \multicolumn{3}{|l|}{ Get nutrition education } \\
\hline Yes & 270 & 70.1 \\
\hline No & 115 & 29.9 \\
\hline \multicolumn{3}{|c|}{ Get printed nutrition education material } \\
\hline Yes & 126 & 32.7 \\
\hline No & 259 & 67.3 \\
\hline \multicolumn{3}{|l|}{ Get visual nutrition education } \\
\hline Yes & 149 & 38.7 \\
\hline $\begin{array}{l}\text { No } \\
\text { Social support }\end{array}$ & 236 & 61.3 \\
\hline Strong social support & 59 & 15.3 \\
\hline Moderate social support & 110 & 28.6 \\
\hline Poor social support & 216 & 56.1 \\
\hline
\end{tabular}

Table 4: Bivariate and multivariable analysis of factors associated with dietary practice of diabetes patients who are on treatment follow up at Felege- hiwot referral hospital, Bahirdar city, Northwest Ethiopia 2017. 


\begin{tabular}{|c|c|c|c|c|}
\hline \multirow[t]{2}{*}{ Variables } & \multicolumn{2}{|c|}{ Dietary practice } & \multirow[t]{2}{*}{ COR $(95 \% \mathrm{CI})$} & AOR $(95 \% \mathrm{CI})$ \\
\hline & Poor & Good & & \\
\hline \multicolumn{5}{|l|}{ Residence } \\
\hline Urban & 103 & 172 & 1.0 & 1.0 \\
\hline Rural & 77 & 33 & $3.90(2.42-6.27)$ & $3.75(2.12-6.63) * *$ \\
\hline \multicolumn{5}{|l|}{ Age } \\
\hline $15-30$ & 59 & 49 & $2.41(1.17-4.98)$ & $1.28(.44-3.68)$ \\
\hline $31-60$ & 106 & 126 & $1.68(.86-3.30)$ & $1.48(.59-3.72)$ \\
\hline$>60$ & 15 & 30 & 1.0 & 1.0 \\
\hline \multicolumn{5}{|l|}{ Educational status } \\
\hline Unable to read and write & 70 & 42 & $3.33(1.83-6.07)$ & $1.81(.61-5.34)$ \\
\hline Able to read and write & 37 & 36 & $2.06(1.07-3.94)$ & $1.21(.43-3.39)$ \\
\hline Grade 1-8 & 26 & 43 & $1.21(.62-2.37)$ & $1.28(.46-3.61)$ \\
\hline Grade 9-12 & 20 & 30 & $1.33(.64-2.77)$ & $1.26(.49-3.18)$ \\
\hline Diploma and above & 27 & 54 & 1.0 & 1.0 \\
\hline \multicolumn{5}{|l|}{ Occupation } \\
\hline Farmer & 57 & 24 & $1.82(0.88-3.75)$ & $1.68(0.54-5.17)$ \\
\hline Civil servants & 45 & 91 & $.38(0.19-.75)$ & $.86(.32-2.32)$ \\
\hline Merchant & 17 & 33 & $.39(.18-.88)$ & $.87(.29-2.59)$ \\
\hline Housewife & 31 & 34 & $.70(.34-1.45)$ & $.51(.18-1.45)$ \\
\hline Daily laborer & 30 & 23 & 1.0 & 1.0 \\
\hline \multicolumn{5}{|l|}{ Wealth status } \\
\hline Poor & 71 & 57 & $1.66(.85-3.27)$ & $.84(.35-2.03)$ \\
\hline Middle & 52 & 84 & $.98(.51-1.90)$ & . 73(.32-1.69) \\
\hline Rich & 39 & 82 & 1.0 & 1.0 \\
\hline \multicolumn{5}{|l|}{ Type of DM } \\
\hline Type 1 & 67 & 62 & 1.0 & 1.0 \\
\hline Type 2 & 113 & 143 & $.73(.48-1.12)$ & $1.30(.70-2.43)$ \\
\hline \multicolumn{5}{|l|}{ Duration of DM } \\
\hline$<5$ & 110 & 99 & $3.93(2.01-7.71)$ & $2.81(1.21-6.50) *$ \\
\hline $5-10$ & 57 & 60 & $3.36(1.65-6.87)$ & $2.79(1.15-6.73) *$ \\
\hline$>10$ & 13 & 46 & 1.0 & 1.0 \\
\hline \multicolumn{5}{|l|}{ Nutrition education } \\
\hline No & 89 & 26 & $6.73(4.07-11.15)$ & $5.88(3.30-10.48)^{* *}$ \\
\hline Yes & 91 & 179 & 1.0 & 1.0 \\
\hline \multicolumn{5}{|l|}{ Physical exercise } \\
\hline No & 118 & 78 & $3.10(2.04-4.70)$ & $1.12(.64-1.96)$ \\
\hline Yes & 62 & 127 & 1.0 & 1.0 \\
\hline \multicolumn{5}{|c|}{ Make choice when Eating out } \\
\hline No & 113 & 59 & $4.17(2.72-6.40)$ & $3.49(2.09-5.83) * *$ \\
\hline Yes & 67 & 146 & 1.0 & \\
\hline \multicolumn{5}{|l|}{ Social support } \\
\hline Strong social support & 13 & 46 & 1.0 & 1.0 \\
\hline Moderate social support & 40 & 70 & $2.02(.98-4.19)$ & $2.09(.90-4.86)$ \\
\hline Poor social support & 127 & 89 & $5.05(2.58-9.89)$ & $3.84(1.74-8.46) * *$ \\
\hline
\end{tabular}


Note: $*=$ p-value $<0.05, * *=p$-value $<0.01$ and $\mathrm{DM}=$ diabetes Miletus, $\mathrm{COR}=$ Crude Odd Ratio, $\mathrm{AOR}=$ Adjusted Odd Ratio

\section{Figures}

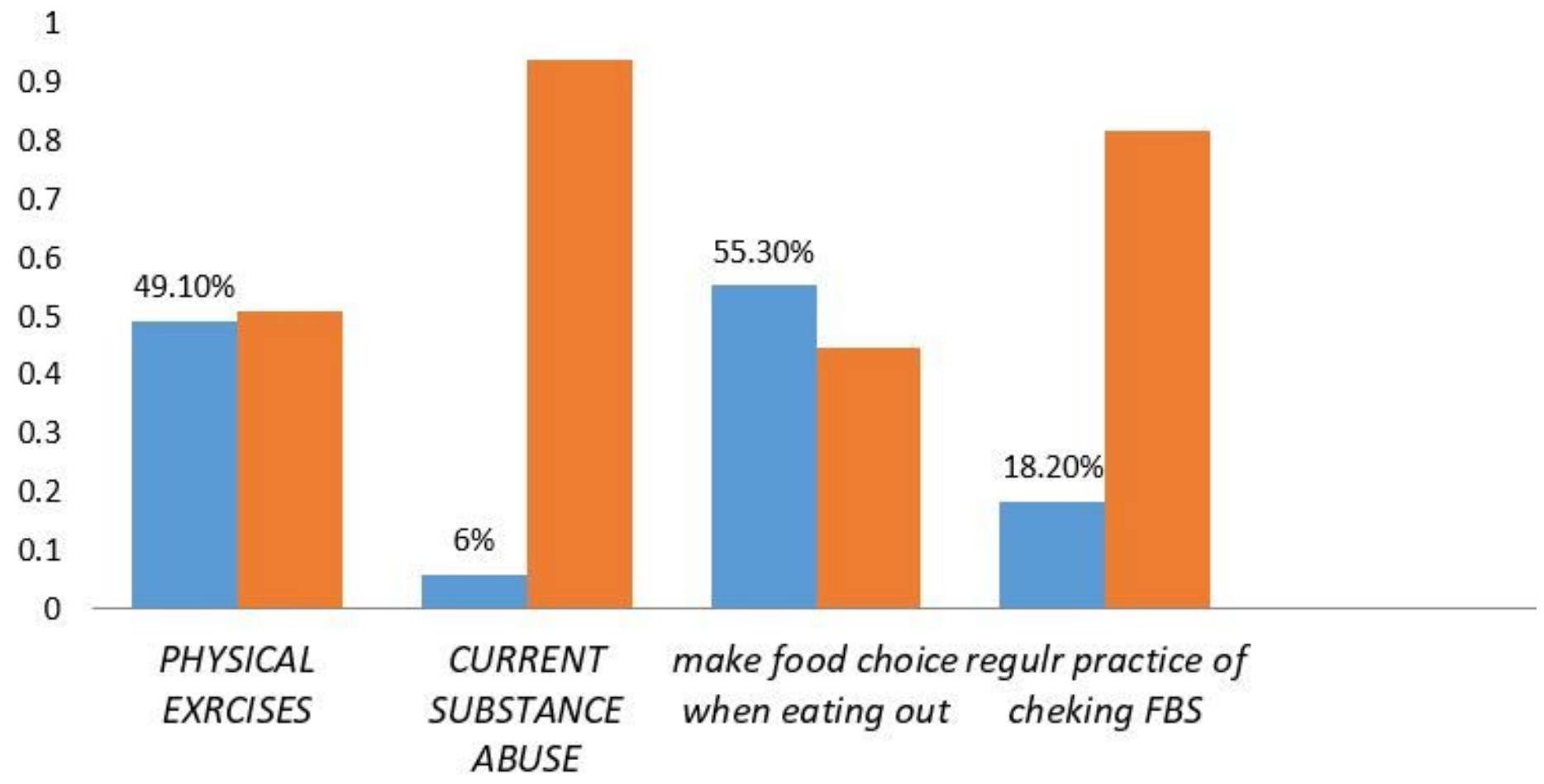

Figure 1

Psychosocial factors of dietary adherence among diabetes patients who were on treatment follow-up at Felege-hiwot referral hospital, Bahirdar city, Northwest Ethiopia 2017. Legend: Yes - blue, No - orange 